\title{
Indigenous Polygyny in Dhofar: (Re-)Interpretations of Individual Options and Daring Delineations
}

\section{Annemarie Profanter ${ }^{1}$ Stephanie Ryan Cate ${ }^{2}$}

To cite this article: Profanter, A. and Cate S. (2019). Indigenous Polygmy in Dhofar (ReInterpretations of Indiviudal Options and Daring Delineations. Al Raida, 43(1), 11-33.

(C) 2019 The Author(s)

Corresponding author: Annmarie Profanter

Author contact: annemarie.profanter@unibz.it

Article type: Research article

Article accepted: $10^{\text {th }}$ August 2019

Published online: 30 ${ }^{\text {th }}$ September 2019

Publisher: Arab Institute for Women

Publication support provided by: Escienta

Journal ISSN: 0259-9953

Copyright: This is an Open Access article, free of all copyright, and may be freely reproduced, distributed, transmitted, modified, built upon, or otherwise used by anyone for any lawful purpose. The work is made available under the Creative Commons Attribution (CC-BY) 4.0 license. 


\section{Indigenous Polygyny in Dhofar: (Re-)Interpretations of Individual Options and Daring Delineations}

\section{Annemarie Profanter ${ }^{1}$ Stephanie Ryan Cate ${ }^{2}$}

${ }^{1}$ Faculty of Education, Free University of Bozen-Bolzano, Italy

${ }^{2}$ University of Alabam, Huntsville, USA

Abstract

Polygyny is widely practiced across Dhofar, a region located in the Sultanate of Oman, reflecting the resiliency of Islamic family law. However, as the country is accommodating transnational influences polygynous marital arrangements are undergoing changes. Drawing on qualitative data collected within a large-scale quantitative study comprising a sample of 1,192 respondents on polygyny in Dhofar between 2004-2010, the entanglements between religious mores on, and cultural practices of polygyny are discussed through individual case-work analysis. First, it is argued that polygynous marriage remains a pragmatic arrangement in the context of tribal relationships. Second, the tension in redefining gender roles is manifest primarily in this marital arrangement. Third, through cultural flow and technological, economic, and educational changes, re-interpretation of mating strategies are encompassing a slow shift from pragmatism to romanticism. The digital nature of communications and cultural identity acquisition in the twentyfirst century continues to influence and guide the manifestations of change presented by the data that show the small but vital steps being made by men and women that are redefining and reinterpreting polygyny and society as a whole.

Keywords: Arabian Gulf, consanguineous polygyny, cultural flow, indigenous systems, multicultural adaptation 


\section{Striving to Get a Word in Edgeways: The Female Perspective}

I am a good Muslim woman from a strong tribe. We are original Bedouins and have always been here. I finished high school and after[wards] married a good man. My husband is a big man. His job in the ministry is very important and he is good with business. We own many buildings and have restaurants and tailors. We were married five years when my husband decided it would be good to have a second wife. We already had three children and our businesses were growing. I had some cousins that were of marriageable age and one that I really liked. They all lived near my mother's house in this one neighborhood. Many people in our ashira live in this part of the city. My mother and aunties held majlis [(in-)formal tribal gender segregated meetings] where we discussed who would be the best co-wife for us. We decided together which one would be the best choice. Because we are successful, we are very busy and we need many children and women to fulfill our duties.

The story of Khyer, a Dhofari spouse in a long-term polygynous marriage composed of one husband and four wives, is a common one in the Sultanate of Oman. In the quote, above she elaborates upon her position as first wife and illustrates how the addition of other wives from within the immediate family resulted in what she perceives as a more solid marriage. She and her family have resided in the regional capital for over 25 years. Her story stands emblematically for all those stories that have fueled this article but cannot be told here in length. The women and men who were willing to share their experiences over the course of this eight-year study ${ }^{1}$ shed light on some of the ways in which this Muslim society approaches accommodating new societal infrastructure and age-old marital traditions. The picture is one of complex relationships, drawn between patriarchs, consanguineous spouses, and marital positionality. The research focuses on participants' responses as individuals to a communal system that has been in place for over 1,000 years and that has been (re)interpreted and negotiated over time. In this article, interpretations of women's and men's experiences of polygynous marriages in the early twenty-first century are discussed, using the women's and men's own words to identify the framework that underpins the polygynous, tribal society of the southernmost region of the Sultanate of Oman, Dhofar ${ }^{2}$. This paper argues that the entanglement of religious and cultural practices both shape and frame marital practices, while at the same time these religious and cultural mores are being (re)interpreted and (re)constructed through people's individual explanations and collective 
practices. The question arises, then, how does this process of mutual interference become manifest in women's individual (re)interpretations and reconstructions? Specific conditions regarding the roles of the female and male spouses are being called into question owing to a confluence of factors such as education, cultural flow, and exposure to different cultural mores and values, changing Islamic interpretations of shari'a law, and concepts of equality.

To date, researchers on polygyny have focused mainly on women's and children's perspectives on the following issues: The impact of this marital form on children's and wives' psychological well-being (cf. Meekers \& Franklin, 1995; Al-Krenawi, 2001); their social and family functioning (cf. Al-Krenawi \& Lev-Wiesel, 2002; Al-Krenawi et al., 2002); their economic status (cf. Ali et al., 2004); the mental and overall health implications for women and children; the fertility rate, marital satisfaction, and emotional distress as women and children experience it (cf. Fatoye, Adeyemi, \& Oladimeji, 2004; Sueyoshi \& Ohtsuka, 2003); (in)justice in polygynous marital arrangements (Profanter \& Cate, 2009a); as well as the acquisition of baseline demographics (e.g., male/female ratio, number of children) (cf. Kosack, 1999). Little research on the topic has been done from a holistic approach. Focusing on the southernmost region of the Sultanate of Oman, this study tries to fill the gap, giving a voice to women from a range of educational backgrounds and tribal affiliations.

\section{A contextual framework}

Oman today is a union of both the northern and southern regions of the south-eastern Arabian Peninsula, yet the two areas remain separated by huge desert regions and hundreds of cultural differences.

The Sultanate of Oman is a country famed within the Gulf for its willingness to embrace new modalities of interaction while at the same time developing indigenous methods based upon those modalities. This is often attributed to Sultan Qaboos bin Said Al Said who is related by blood to both northern and southern Omani tribes. Thus, Said's own bloodline exemplifies how arenas that are often kept separate are now finding new avenues in which to connect.

It should be noted that in the Arabian Gulf, three principal levels of family structure exist within the context of native tribal systems: The tribe (qabila), clan (ashira), and extended family ('ayla). It is the alliances and ethical obligations highlighted in the kinship folk model that shape 
almost all individual and group pattern behavior, thus, reinforcing the sense of communal consensus. The net of relationships within this system extends throughout many generations and connects each tribe with its branches (Peterson, 2004). Gulf society, except for Bahrain, is structured around the qabila and its satellite tribes composed of smaller extended family groupings called ashira and the intimate family, 'ayla. The qabila's position within the societal hierarchy has historically rested on two factors: 1) degree of relationship to the Prophet Mohammed-a few qabila can trace their lineage to the Prophet or his disciples, thus, insuring societal regard and a high position; 2) tribal strength - strength is determined by variables such as number of male members, degree of acknowledged wisdom, piety, grazable lands, and size of camel/cow herds. The northern region of Oman is composed of a mix of Baluch, Lowati, Zanzibari, and native Omani tribes, whereas the southern region, Dhofar, consists predominantly of indigenous tribal groups with historical residence dating back thousands of years. The Dhofar region has retained a homogenous cultural milieu for thousands of years and is largely influenced by the Mahra and Hadramawt regions of Yemen and Eastern Africa (Peterson, 2004). The tribal people of Dhofar are primarily Bedouin-Arabs, a term that was traditionally used to describe pastoral people who herded camels and goats, but is now more colloquially used for all the nomadic people of the Arabic-speaking Middle East.

The Sultanate implemented its first complete census in 2000 and determined that the general population was 2.3 million (Al-Lamky, 2004), with three-fourths of the population of the Dhofar region inhabiting the capital of Salalah and the surrounding area. Salalah, a growing urban center in Dhofar, is a rapidly developing economic and social area facing challenges to its traditional modes of social control yet continuing to adapt them to its changing needs. Since the discovery of energy resources on the Arabian Peninsula and developments in intercontinental transportation in the early twentieth century, transnational cultural exposure has grown exponentially.

Yet, the family structure described above still forms the basis of the Dhofari society and the characteristics of the tribe are of key importance: The strength of the spouse's tribe and the communal compatibility of the two groups, and the need for consanguineous match are important marital concerns (Low, 2005, p. 65). Thus, marriage is primarily a communal process involving male 
and female members of the extended family, as well as elders from the larger tribal grouping, all of whom participate with the primary aim of furthering the well-being of the group. Pairings are ideally developed first from within the ashira/'ayla to solidify social standing and financial security. More and more often, partners are found from the wider qabila as well owing to the influence of a desire for a more intimate or romantic liaison. Gulf society places males, and specifically husbands, not only as heads of household, but as the penultimate decision-makers regarding their female relatives. This prescription was intended to maintain tribal strength and clarity of focus (Profanter \& Cate, 2009a). However, as seen in the introductory story, practical application of major decisions often begins with the woman's networks and is then presented to the patriarchs as a fait accompli. The marital system is based on the regional interpretation of historic Qur'anic guidelines, which shall be summarized in the following paragraph. In the region, it is important to recognize, however, that Islam has intermingled with many other elements such as local tribal customs, politics, and economics, and these historical conjunctures have influenced the interpretation of Islam (Bonney, 2004).

\section{Polygynous Blessings: An Islamic Perspective}

Polygyny as a marital strategy was practiced long before Islam emerged from the arid regions of the Arabian Gulf. It has existed in a multitude of forms and in myriad cultures through innumerable centuries, yet it was not until the advent of Islam that it was codified and applied indiscriminately across cultural borders, imprinting a contemporary prototype upon this ancient practice (Chamie, 1986). According to Al-Hibri (2001) the Qur'an was revealed to cultures already steeped in polygyny where men married more than a hundred women at a time. In Islam, polygyny is legitimized by both the Qur'an and the hadith (Yusuf, 1983: Sura IV, Verse 3) 3 .

The Prophet Mohammad provided the basis for the actual rules and regulations concerning polygyny within Islam. Muslims believe that he is the last of a long line of prophets, and was concerned with the treatment of women in Arabian society. He felt that leaders of the tribe were not able to properly follow cultural guidelines and care for all members equally (Armstrong, 2000). His intention was to create a system of social justice and equity (Lippman, 1995). Polygyny in its original Islamic form encompassed the care of widows and orphans who were left without family protection after war by incorporating them into existing family systems (Hassouneh- 
Phillips, 2001). Moreover, in the time of Mohammad some of the restrictions imposed upon polygyny were intended to limit adultery and protect women from masculine excesses (Husain, 2000).

The implementation and spread of Islam saw a number of revolutionary rights for women established (e.g., the right to inheritance, property, marriage, and divorce.) The Qur'an prescriptively regulates various aspects of daily living, and contains judicial guidelines, ethical principles, and outlines executive powers of governance (Mashhour, 2005). Islamic law does not encourage polygyny, but it does assert that women should be married for their own protection; thus, polygyny has been seen as a way to sustain the public well-being. The Qur'an both sanctions and limits the practice by stating, "marry women of your choice, two, or three or four; but if ye fear, that ye shall not be able to deal justly [with them], then only one" (Yusuf, 1983: Sura IV, Verse 3). Traditionally, polygynous units were interdependent in the domains of work, food, childrearing, and education. In contemporary times, these domains have separated, in part due to the change from pastoral to sedentary living situations and the influx of globalized mass culture. Currently, women in the tribal Dhofari region of the Sultanate of Oman experience both traditional and contemporary incidences of neglect, isolation, empowerment, and (in)validation associated with these polygynous unions.

At various times, the historical message of Islam has been interpreted in a more progressive, liberal, and secular way regarding laws and institutions. However, according to Mohammed Shahrour (1990), a famed liberal reformer and scholar of Islamic thought whose work has been banned in the more fundamental strongholds of Islam, a trend in more literal interpretations promoting a return to a purely Islamic society is emerging.

At the international level, "the shari'a as a code of laws underpins the Universal Islamic Declaration of Human Rights (UIDHR)" (Hilsdon \& Rozario, 2006, p. 333) and also specifically addresses family concerns from the different parties' perspectives. Some international bodies currently are in debate regarding the definition of equal rights, and whether or not, and to what extent, the UIDHR differs from the Universal Declaration of Human Rights (UDHR) or The Convention on the Elimination of All Forms of Discrimination against Women (CEDAW). This arises not only due to semantics, but also because of how each framework defines gender (Mayer, 1995, 
pp.79-92; Bielefeldt, 2000, p. 105). In the course of debating this issue, both the World Conference on Human Rights in 1993 in Vienna and the United Nations Decade for Women Conference in 1995 held in Beijing uncovered the omission of the family unit from within the UDHR's definition of human rights, and "goaded those bodies into extensive discussions regarding the edicts regulating familial issues between males and females in matrimony, divorce, inheritance, guardianship, and child custody" (cf. Kazi, 1997, pp. 141, 143; Hilsdon \& Rozario, 2006, p. 334; Bielefeldt, 2000, p. 111).

Among Muslims there is also an ongoing argument regarding polygyny: Reformists are convinced that it is not appropriate in this day and age, while traditionalists maintain that it is the right of all Muslim men stated in the Qur'an, the recorded word of God, which cannot be changed (Goodwin, 1994). As Charrad (1998) states, the cultural influence throughout the Islamic world impacts the idea of a separation between religion and culture, by clearly espousing the dogma that there is no separation between church and state, there is no separation between the world of the physical and the spiritual, and that the laws of Allah are applicable in each and every life situation. Progressive Islamic scholars such as Shahrour (1990) argue that exposure to transnational influences has led to a trend in more literal interpretations, promoting a return to a "purely" Islamic society. The dichotomy that exists between pragmatism and traditionalism is not just isolated to these communities but exists to various degrees in Muslim communities around the world.

The heart of Islamic teaching is that religion is not just a part of life, but that life is only a tiny part of religion; thus, everything in life is prescribed by Islam, yet culturally interpreted and shaped. As such, Islam is a sociopolitical, socio-religious, socioeconomic, educational, legislative, judicial, and militaristic system reinforcing the tenets of what is believed to be the true faith. According to Samir Al-Adawi, Rustam, and Ihsan (1997), women's roles may be changing slowly moreso because of specific Omani Bedouin traditional society pressures, rather than because of Muslim beliefs regarding those roles. To be more specific, indigenous tribal practices strongly influence women's roles relative to Islamic teachings and interpretations.

My daughters must know how to read, write, and calculate - they must have their own money. If they have their own money, they can leave if their husband's family decides it is 
time for a new wife. The tribes are very strong, the pressure is very hard. My husband had a problem, his mother wanted him to marry a cousin from the jabal (mountain), she wanted a grandson and we have only daughters. Islam says that you may marry again if you can be fair and if there is a problem in the house. We had no problems but the Jebali's wanted grandsons and they pressured my husband. I knew there was a problem but my in-laws would not tell me about it. I had started my perfume business and it was growing. It was in my name and I told my husband I did not want another wife and if she came I would leave. Divorce is not good here, it is bad for the tribe and the family. For months we had a problem - my husband became more and more quiet and tired. I would not give in I did not want another wife.

Shamsa ${ }^{4}$ is a businesswoman and mother of three daughters; her quote reflects the struggle of tribal priorities relative to Islamic guidelines and Ibadi tradition. Dhofari women's societal conditions are not separable from the state of polygyny, which has historically been the primary marital system in this area. Marital concerns have centered around the strength of the spouse's tribe, the communal compatibility of the two groups, the need for a consanguineous match, and the notion that "a female's value as a mate is her reproductive value" (Low, 2005, p. 65). Dhofar society is changing at its own pace, and that pace is in keeping with the law of Islam- shari'a - the basis of the judicial system throughout Oman.

The contours of daily life, as constructed by Shamsa, indicate that traditional, normative coping strategies within this region include: embracing existing religious strategies, communal participation and prayer, adherence to religiously defined gender and sexual roles, and polygyny. Other coping strategies include the involvement of extended family; development of sibling relationships with all paternal descendents; veneration of the patriarch; maintenance of intergenerational residences; tribal relationships; encouraging open communication; stabilized tribal connections through intermarriage; and adherence to all majlis (tribal council) rulings. Nontraditional, maladaptive tools for societal integration include: mind or mood altering substance misuse, which is considered haram (forbidden), and internet misuse, using web sites as coping mechanisms and escape routes. Non-traditional, adaptive, societal support frameworks include: developing businesses or farms; increased internet usage; Islamic women's chat lines; daily Qur'anic e-mail messages; and pious marriage websites. Looking at the availability of technological advances in the last 20 years can help map a contemporary generational response to marriage 
and cultural patterns including marital arrangements, intra- and inter-tribal relations, and education. Control over society members is exercised quite differently on the Arabian Peninsula as compared to non-tribal Arabian societies and western cultures. In the west, as children age they are expected and encouraged to exert more independence and develop self-control, thus minimizing parental involvement and control. However, in Muslim societies in the Gulf, as children develop, their importance to the tribe increases; thus, major life decisions are considered vital to the communal welfare and as such, depend upon parents and tribal elders. So, parental control is inversely proportional to age in the West and reversed in the Arabian Gulf (cf. Kalwar \& Ahmed, 1989, p. 92). This is reflected in Shamsa's husband's response to parental and ashira pressure to add another wife.

Women's intergenerational experiences of courtship ritual in the Arabian Gulf Region have been impacted by the rapid cultural shift relating to information technology (I.T.) and its associated tools, including mobile phone technology and internet access. The effects that the use of these devices has had on the manufacture of contemporary cultural practices are drastic. The affordability of such technology has opened a door into communication between the sexes, which appears to violate or border on violating age-old tribal laws and taboos (Bunt, 2018). This historical, tribally structured Islamic arena is one in which courtship was traditionally associated with the guardians or purveyors of a marriage, not necessarily the participants. This was in response to strict adherence to interpreted Qur'anic guidelines regarding male and female contact outside of marriage or close familial networks (Shukri, \& Owoyemi, 2014, p. 59). Those guidelines define the extent and conditions of both courtship and marriage. The manufacture of culture is one where information technology's influence is being seen more clearly in this relatively affluent region where I.T. tools are readily accessible to almost all economic classes. Initial statistical analysis shows significant effects and signs of experienced cultural norms including economic, social, and emotional factors.

\section{Methodological Considerations}

\section{Sample}

Building on the authors' six plus years of research experience from 2004-2010 in the Arabian Gulf with a focus on polygynous communities, a large sample of women, men, and

Publication support provided by eScienta (www.escienta.com) 
children involved in some type of polygynous family life were included in a large-scale study. ${ }^{5}$ The consanguineous polygynous family system extended not only inter-generationally, but also internationally, connecting tribal branches throughout the Saudi Arabian Peninsula: Oman, Yemen, Saudi Arabia, Kuwait, UAE, and Bahrain. By working at various educational institutions in the Arabian Gulf, the human network which informed the ongoing research in this field gradually grew to encompass pastoral tribes as well as satellite tribal members living isolated from their homelands. This original study, based in the Dhofar, developed into a Gulf-wide assessment of the interrelationships found in polygynous marriages, and includes a sample of 1,192 Arab Muslims including women, men, and children (Profanter \& Cate, 2009a, 2009b; Cate \& Profanter, 2007a, 2007b). All families included in the analysis lived in the southernmost region of the Sultanate of Oman. ${ }^{6}$ The female and male respondents quoted in this article stretched across the spectrum educationally, from those with only madrassah education to those with higher degrees in western secular educational settings both from within the Gulf and globally. Thanks to the informal contacts developed in the community, it was possible to include respondents outside of university networks. Economically, there were those who continue to lead lives based on traditional subsistence patterns, such as pastoralism and farming within the ravines, oases, and mountains, as well as those living a contemporary life based in private business, governance, the military, travel, or other infrastructure dependent sectors.

\section{Recruitment}

The presence of one of the authors as an active participant in both the formal and informal social and educational settings afforded us the opportunity to build relationships and extend the personal network of interviewees through the Arab system of wasta ${ }^{7}$ and the referrals we received through word of mouth. For example, in Salalah women held a regular Friday morning majlis, including three generations of tribal women, and the authors were regularly invited due to their roles as teachers of one of the woman's daughters, which affords high standing within this Islamic society. That relationship then led to other opportunities to pariticipate in community events, such as wedding celebrations and engagement parties, and so the web grew. ${ }^{8}$

\section{Procedures}

Publication support provided by eScienta (www.escienta.com) 
The recollections of Muslim women and men, and their detailed and illuminated personal perspectives on arranged marriages, conflict management techniques, and coping strategies within polygynous unions were gathered using interviews and participant observation. In the open-ended, in-depth interviews carried out jointly as a female research team, the topic under investigation was approached holistically by concentrating on personal life histories, motives, and explanations, so as to give a fuller picture of the men's and women's experiences. The interviews were conducted in English and Arabic depending on the language proficiency of the interviewee. This was done to give interviewees the opportunity to fully express themselves without any language constraints. While the original study adopted semi-structured questionnaires, the 16 interviews interpreted for this paper were recorded and transcribed verbatim. For the translations, local female research assistants were hired.

\section{Validity}

Adopting a snowball sampling method within this qualitative approach granted the authors access to a great variety of individuals in a rather closed society. Not aiming at generalizations, it was possible to identify main structural aspects that can be noticed in other cases of the same class.

It was critical, however, that the researchers took steps to ensure the reliability and validity of the findings: To ensure a) external validity (a thorough description of the context of the research is included to allow for transferability of the findings); and b) internal validity (the richness of the data and interpretations actually reflect the views of the participants as confirmed adopting the method of triangulation by obtaining confirmation of researchers' interpretations by participants themselves). In the course of this study, not only did the authors interpret the data but, in 2011, a documentary based on this work was filmed in conjunction with some of the participants. In 2012, the written accounts were presented to the participants and the documentary was shown to focus groups in both the southern and northern regions of the country. The data interpretation was thus validated in light of changing approaches to Omani society, tribal influence, and women's roles. And finally, the authors have attemted to ensure confirmability, in other words, interpretations of the data by other researchers demonstrated that no inappropriate or subjective biases impacted the analysis process. And finally, reliability or dependability, which is ensured 
through thorough documentation of all aspects and circumstances of the research procedure so that legitimacy is lent to the research method. Adopting these measures, the authors aimed to make sense of, and recognize patterns among participants' world-views and perceptions in order to build up a meaningful picture without compromising richness and dimensionality.

\section{Love Times Four: Perceptions on Polygyny}

In the Muslim Arabic cultures of the Gulf region, Islam is the thread that runs through indigenous institutions as well as through societal frameworks borrowed from other cultures. Power lies, ideally, with the eldest male member, while females, regardless of age, have less influence on issues of law, leadership, and economy. Yet, within the confines of the home, women are responsible for overall maintenance, networking, and nurturance/child care (Hilsdon \& Rozario, 2006). However, due to changing economic imperatives as well as relational emotive desires, and accessible inter-gender education and contact, this ideal varies significantly from the reality. In rural areas, as opposed to modernized oil economy cities, people still depend upon a pastoral economy of grazing, camel breeding, and fishing, with its jealously guarded tribal territories and rights. These culturally persistent tribal livelihoods and the kinship networks they depend on continue to inform marital relationships today, and the researchers remain intrigued by how these pre-existing relationships reflect on polygynous success/distress. Aida observes, albeit a bit idealistically, that one of the social consequences of polygyny is that "tribes become close and sisterly, [and] make the family closer by marrying relatives; it creates love among both families, and happiness between husband and his wives." This, as stated above, is an ideal; however, the underlying tenet is that marriage is a Muslim imperative and, as such, should be sought after and welcomed regardless of the compromises needed. For all interviewees, the injunction to marry inter-tribally was seen as still relevant if not always possible due to societal position.

Layla Al-Wahibi, a first wife from Taqua, comments: "Not much changed because we were married a long time because in the beginning I used to get everything from him; love, time, and care; now only money. My living changed for the better because he gave me a good sum of money, and I started a small business. He also gave me a piece of land in Muscat." Her affect during her response to the question of how her marriage changed with the addition of a new wife reflected

Publication support provided by eScienta (www.escienta.com) 
what she held to be of primary importance, her financial security. Nonetheless, as seen from the beginning of her statement, there was an emotional, romantic element to the early marriage which gave way to a more traditional pragmatism.

In many cases, especially due to current multi-cultural factors, there is underlying tension and conflict. At a women's Friday afternoon majlis in a comfortable sitting room, the topic of a tribal member's marriage as a third wife came up and some of the women commented on their personal feelings around polygyny in their town. Fatma, a college student, shared: "I don't believe in multi-marriage but it does have social advantages; it solves the problem of unmarried girls and it helps first wives in housework." Rasha concurred, noting that "because I have spent the last six years getting a higher degree I am old and it is hard to find a husband for me. So I will probably end up as a second or third wife to an old jabbali [mountain tribe] man. What to do, we have to get married." In another interview, Hamed stated, "it is vital to fulfill your duty but it is also good to have nice feelings," and he stressed his dilemma over trying to balance the pull toward some type of romantic love against the need to fulfill his "duty" by noting that, "I married the first [wife] because marriage is a life obligation and she was my cousin and in Islam, marriage is half of religion. As for my second wife, I married her because I fell in love. I didn't marry the first for love but after marriage love grew between us and now I love both my wives and I cannot live without them. I am fair with all my wives and I treat them equally." As shown in the interview extract, in Dhofari society marriage remains a pragmatic arrangement, although more people are starting to desire a romantic attachment prior to formalizing the bond (Mammen, 2019).

\section{Gender Roles in Transition?}

It is still the norm within the smaller cities and rural regions for women to remain within the family stronghold and see to the daily needs of the extended family (Grossbard-Shechtman \& Neuman, 1998). Women's status continues to be strongly based on being married and rearing children, especially boys. A good wife and mother is expected not to be absent from her husband's home except for everyday chores and visits to other members of the ashira, for the purpose of strengthening and maintaining ties. She is expected to be self-sacrificing for the sake of the family, and to uphold the family honor by acting as a devout Muslim woman at all times. Regardless of their educational status, most women interviewed stated that marriage is integral for human 
happiness and societal functioning. In keeping with their beliefs, the women noted the importance of tribal norms and how they could constrain an individual's life choices.

The following comments support those beliefs, that a woman must marry in order to fulfill her societal role regardless of marital position, meaning whether she is a first, second, third, or fourth wife: "My father agreed for me to marry my husband without asking for my permission. If a man treats all wives equally and helps to decrease [the] number of unmarried women in society, then it is all right. It is a known fact that there are more females in our society than males," says Layla as she takes another date with her cup of ghawa (coffee). Nevertheless, even women who have stepped more fully into the new and modernized pan-Arab ${ }^{9}$ brand of modern womanhood, deal with the lack of infrastructure that encourages and supports such pursuits from an individual perspective. For example, Abeer indicates this by saying: "My university time has had lots of absences because I am exhausted, and my life is very full because my family stays awake all night and then we talk so I can't get up because I am the only lady in university, all my other sisters are married or doing business." Many career women, even those attaining high levels of success, defer to their spouse or family for major decisions (Hoodfar, 1997; Shalhoub-Kevorkian, 1997). As Hatoon reports: "I had studied at university but I was too old when I got married and my father accepted and I was married as a second wife."

Women's roles in polygynous unions are influenced by the nature of Islamic teachings, the evolution of shari'a, and the understanding of Islam which indicates that, in fact, there should be common ground between gender equality and Islamic law (Mashhour, 2005). However, scholars' re-interpretations and judicial applications are to be seen in light of tribal needs and interpretations. For example, some interviewees related obstacles such as being able to give birth only to girls when their husbands wanted boys, being infertile, attempting to direct the next remarriage to make for a happier family, and issues around emotional satisfaction almost always being related to the husband and not to the wife. Mohammed repeatedly told us: "It was a personal opinion of mine, because after I divorced the first wife I looked for another wife and I married the second wife and then divorced her and married the third wife and she only gave birth 
to one sick boy so I married the fourth wife hoping she will give me male children." Hamood comments on his perception of how vital it remains to have sons to continue the family traditions and how polygyny has had an impact that was, "very positive because without my sons, I wouldn't have been able to fulfill all the demands of the family." He added, "when my sons worked with me in my companies, we developed a huge source of income for the family." Clearly, men continue to be autocratic rulers maintaining the right of veto concerning all matters within the household. They also continue to hold most of the financial and governmental power, with women having to negotiate their external societal participation from within the parameters of their traditional roles. However, the change represented by these stories are ones showing the small but vital steps being made by both men and women, who are redefining gender roles within polygynous relationships and society as a whole. But, these stories also reveal the tensions associated with redefining gender roles, and the tight parameters limiting and defining what is socially acceptable. These stories lead us to the question of how modern pressures are superimposing a schism over the application of Islamic guidelines in people's daily lives, or in some cases, are helping to moderate co-wife conflicts as exemplified in the next section.

\section{Areas of Conflict and Coping Mechanisms}

"Of course, any women whose husband remarries will suffer. She feels unwanted and unloved. This is how you feel when your husband decides you're not good enough for him and goes for another woman. This is horrifying and leads to so many problems." The statement of Fatima, who discusses her feelings about polygyny and her response to the addition of a second wife in her family, was surprising in its boldness and willingness to concretely address her emotional needs without placing her husbands' feelings first.

The Qur'an clearly deals in the sura with issues surrounding the implementation of a polygynous union, as reflected in the interviewee's statements. The interpretations of those Islamic tenets vary across different schools of thought. Shahrour argues that any changes in societal realities would require a review of these prescriptions (Shahrour cited in Marcotte, 2001, p. 321). However, transnational pressures, booming economies, and rampant urbanization are succeeding in loosening societal stanchions that have served to anchor these tribal Muslims within their religious and socio-cultural frameworks for centuries ${ }^{10}$. For example, the concept of justice 
is widely applied, even though it is often ambiguous in definition (Profanter \& Cate, 2009b). In this context, justice, as outlined in the Qur'an, is not clearly defined, and yet, across the board, interpreters of the Qur'an state that justice includes equal treatment in regard to shelter, food, and other basic necessities. Both the women and men interviewed for this research paper were clear in addressing those issues. For example, one evening, at an educational conference at Dhofar University, in response to the interviewer's unmarried status, Mona elaborated: "Good. You can be independent, not like me. I am married but he remarried, and I felt that I was unwanted and unloved. He stopped supporting me financially like his new wife. Sometimes he never gave me any allowance at all, so l'd have to ask my brothers and sisters for money. My family treated me with sympathy because I was the only one whose husband remarried." Zahra, one of the author's student's mothers, shared her experience. She indicated that an injustice had occurred: "He spends most of his time with the second wife and her children and he doesn't pay any attention to us and he doesn't care about us, even though my children love him and respect him very much. He doesn't come to us unless he wants money or if he needs someone to defend him."

These statements are representative of conflict within polygynous marriages and the coping mechanisms women in these marital arrangements might use, including financial strategies, coalition consolidation strategies, and emotional and psychological well-being or dissonance. The following accounts narrate some of the more common areas of conflict and coping strategies that include marital arrangements made by co-wives. Aisha, having lived for a long period in Abu Dhabi but now back in Salalah, exemplifies the consanguineous marriage arrangements that often occur. "All my family agreed. His first wife, who was my sister, had passed away, so my family agreed and encouraged this marriage, especially my older sister who insisted that I agree." She and others commented that it was good to marry your sister's husband as it would make both parties more comfortable. Shams Al-Magram reveals another side to the emphasis on marriage and children by commenting on the marginality of a barren woman in a society that idealizes motherhood. She stressed: "I insisted on his remarriage, and because my first child was a test tube baby and difficult to get I asked my husband to marry my friend and she never changed, and my husband always thanks me for choosing her for him." This observation was 
echoed by Saleema, who noted that "he wanted boys and I had only given birth to girls, so we needed another wife."

The data reveal that the one consistent pattern across educational levels and economic position was the need for and desire to have children. This desire frequently mitigated any individual concerns regarding marrying a second or third wife. Polygyny was seen as a coping mechanism for both women and men in relation to fertility and reproduction. In addition, men displayed a strong tendency toward polygyny based on the desire to have available sexual partners, due to Islamic prescriptions against sexual congress after childbirth. For both men and women a strong tendency among the younger generations toward experiencing a love story within their marriage was reported and will be further discussed in the following section.

\section{Timely Changes in the Polygynous Framework?}

Polygyny and the formation of polygynous coalitions are highlighted in the context of tribal relationships. The practice of marital arrangements is one that impacts the tribe as a whole, its relationship to other qabilas, and the emotional and mental health of the marital partners. ${ }^{11}$ The excerpts below-gathered during an informal discussion regarding the ways in which males place the fulfillment of their tribal and religious responsibilities first, and their individual choices as influenced by peer pressures last-reflects the historical precedence that has guided tribal lives in the region for centuries, and also shows gains in the importance of self-fulfillment among individuals. For example, Ibrahim Al-Shahri's notes: "The first [wife] is a relative, the second I married her to have male children, and the third because of my friends." Another friend, Nasser Tabook, laughingly responds: "When men gather and talk about their wives, one of them may have more than one wife, and says he is happy with a new wife because there aren't any screaming kids and you feel like you're twenty years old again especially if the wife is young. This inspires the rest of the men to get married." The men, although aware of the injunctions against marrying foreigners, often chose to marry one as a second or third wife after fulfilling their tribal duties, even though this goes against the societal norm. The influx of readily available media of all types representing women and men in relationships and situations that are extremely provocative in these cultures has also helped to influence and reinforce the belief in men's predominance in sexual affairs. Yousef Al-Zahrani's remarks are representative of this: "I married my first wife 
because she was my cousin and I loved her a lot. As for her my second wife, I traveled abroad and was away for many years and I married again. I had a friend in that country, I felt lonely, and I met his family and married his sister. Because marriage to us is something a man is proud of when he can have a large family and make them happy." Tacitly, he is fulfilling his needs as a man, even though his choices are also in contradiction to traditional societal standards.

Ali Al-Najd's personal experience highlights the ambiguity often experienced by younger male tribal members who are attempting to merge traditional tribal requirements with individual inclinations in contemporary urban settings. This new pattern of using I.T. tools to expand their marital options is one that, although still marginal, is becoming more common. Young men and women who have found their spouses this way still have to use established societal avenues to legitimize their relationships (Waines, 1982). Ali's search for a second wife reflects his willingness to violate certain societal taboos; he pursued an unmarried woman to whom he had no blood relationship prior to marriage. And yet, he still attempted to reconcile his individual needs and desires with those of the tribe:

I told her, I want to see her. She said I have to tell you something before we met: I am black. I don't want to get married to a black lady. They are not bad but socially not accepted, so I can't marry her because of the tribe and also because her skin is black. Islamic scholars say that you should try to get married to a woman who is equal to you, not in money but in being Arab. ${ }^{12}$ If a lady is from [the] west and you from [the] east it will be difficult to communicate. Islam does not prevent or forbid it but strongly suggests it. Prophet Mohammed's, peace be upon him, friend and disciple, was a slave, called Bilal, who wanted to marry the aunt of the Prophet and it is known he did. This means: it is allowed to marry but not encouraged. I will not feel okay with a very different wife. You see, it is a matter of choice.

In the Arabian Gulf it remains a traditional norm to marry consanguineously; however, marrying into an African branch of one of these tribes is generally not acceptable, as seen by Ali's belief in the proposed fiancée's unacceptability. The advent of internet technology and mobile media has destabilized many sociocultural constructs that have anchored this community. In the face of conflicting transnational traditions, these constructs are being reinterpreted in a new way that strives to be consistent with the letter of the law, but not necessarily with its form. For example, Khalid Al-Rahbi told us that, 
I want a wife who understands me. I am looking for a scholarship, so I was on a website and looked for a wife wh[o] is enthusiastic. I talked to one lady [and told her] that I am divorced and have a son and one on the way. So I told this woman, so if we got married, we should pray, so God will tell us if this marriage is good for us. So she did pray and I prayed. I just talked to her on the website.

His attempt to use the internet in searching for a second wife represents Khalid's desire to escape certain traditional boundaries while at the same time remaining a part of the social context. More importantly, his desire for a marital partner who is his emotional if not intellectual counterpart, is striking in its originality. Here then is the collision of the tribe's norms and Khalid Al-Rahbi's use of cyberspace to achieve something that is in opposition to those norms. It also illustrates his willingness to adapt long-standing cultural principles by publicly abiding by them, while simultaneously redefining them.

Over shisha (hookah) in a small café hidden within a mixed expatriate and Arab residential compound, Yasser tells the story of the rapid changes he has noted in his own community in the recent past:

In the past, the only chance you had to know a woman [was] through the telephone, there was no mobile, so you just pick the numbers, and call hallo, hallo and start. You know it starts with the phone with sweet talk sweet things then they get together first time in the mall, just I see you and you see me, that's it. Next time okay. Now we have so many chances, we have malls, entertainment places, we have café, café internet, so many things, and they can get together, nobody can ask who is she, who are you, what is the relation about you, only the Mutaween [religious police] do not allow it.

As in the case of Ali, who was looking for his second wife, Yasser reflects on how the structures of consanguineous polygyny are being weakened by the advent of transnational IT. Young men are attempting to gain more control over the choice of their second and third wives by circumventing the majlis and familial networks. Although the extent to which both Ali and Khalid will actually push the envelope only goes so far, they still openly address their desires to surpass traditional bounds. However, they both returned to more traditional strategies in the final rounds of pursuing another wife, even though their beliefs about what their marriage should encompass had shifted from pragmatism to romanticism. This indicates a dynamic cultural shift that has 
occurred as a direct result of the region's technological, economic, and educational advancements, all while maintaining a commitment to traditional values and cultural artifacts.

\section{Conclusion}

Tribal choices and individual responses to those decisions continue to evolve and change in response to numerous factors. Participants' explanations of issues regarding polygynous marital arrangements supported observations regarding the influx of external factors on traditional patterns (Profanter \& Cate 2009a). As seen in the stories shared by these men and women in Dhofar, rapid economic development coupled with accessible higher education, IT tools, and affordable international travel are affecting the ways that Dhofaris manifest the marital cultural mainstay-polygyny. How women and men adapt to social pressures and individual desires through polygyny has been outlined in these excerpts. A glimpse into their stories shows how gender roles, individual choices, conflict, and tension are both shaped by and shape traditional means of social control and influence.

The manifestations of change presented through our interviewees' stories show the small but vital steps being made by both men and women that are redefining gender roles both within polygynous relationships and society as a whole. These changes contribute to a reinterpretation of the parameters defining socially acceptable gender relations. The waxing and waning of relational ideals and their pragmatic reflections in daily life reminds us that:

Whenever changes occur in a society and consequently effect social institutions including family, even the roles of these institutions in the society change. This is because the social relations among the people are always effected by the societal changes whether abrupt or slow. (Omari, 1991, pp. 56-57)

The power of social media has been discussed in the literature to contest (unfair) social arrangements (Herrera, 2014). The qualities that make new media so attractive to people seeking change from below have been described by several of our respondents: Women are able to assume active roles in the choice and communication of (future) husbands without violating the boundaries of social norms. However, the enhanced participation of women, while often lauded, is not paralleled by cultural interpretation and application of policies and mores that support the needs of women in regard to their family domains and sociocultural expectations (Al-Lamky, 2004, 
pp. 48-51). Thus, the development of an indigenous societal structure that incorporates components of both systems to best serve the changing needs of this tribal society is crucial.

\section{Notes}

${ }^{1}$ The author has been working in collaboration with Dr. Ryan Cate Gibson on a study of polygyny for six years in the Sultanate of Oman. Their positions at Dhofar University enabled them to have close contact with various tribal qabilas and ashiras.

2 Commonly the term "polygamy" covers all manners of plural marriage and is not necessarily associated with a specific religious system. For clarity, the sociological term used throughout this article is "polygyny defining one man and plural wives."

3 The Holy Qur'an, an English translation.

4 The name and tribal relations of the interviewee have been altered to account for anonymity and confidentiality (APA 2003).

${ }^{5}$ Quantitative and qualitative findings were reported in Profanter and Cate 2009a, 2009b; Cate and Profanter 2007a, 2007b. For a detailed overview of the quantitative characteristics of the sample see Profanter and Cate (2009a, 2009b).

${ }^{6}$ This project is part of an ongoing study: With the support of the Ministry of Information of the Sultanate of Oman a documentary on polygynous marital arrangements has been produced by the authors in collaboration with Dutch filmmaker Nederveen (2010-2013). "Polygyny in Oman" was premiered at the University of Alabama in the U.S. in the spring of 2013.

7 The system of relationships based upon favors done and owed which connects the tribes one to another and is a primary moving although hidden force throughout the Gulf world

${ }^{8}$ We especially thank the family of Susan Al-Shahri for their helpful suggestions, and we deeply thank all those in the Sultanate of Oman who assisted us in this research.

${ }^{9}$ Extensive transmission of multi-media in the Arab world originates from the Levantine and North Africa.

${ }^{10}$ For instance, in contemporary Tunisia, polygyny is illegal due to the official determination that a man is incapable of being just to more than one wife.

${ }^{11}$ For a detailed statistical prototype of the variable "marital arrangement" in the Dhofar region, see Profanter and Cate (2009a).

12 In contrast to Ali's statement, the Qur'an explicitly proclaims that God created human beings and divided them into tribes, nations, and peoples to facilitate mutual recognition and interaction, with no claim of superiority or place of pride by one's community over the others. The Prophet said: "The white men do not have any superiority over the black nor the black over the yellow; all men and women are equal before their creator." Muslims are equal before the civil law and this equality was proclaimed at a time when it was not practiced anywhere in the world (cf. Verma, 2000).

Publication support provided by eScienta (www.escienta.com) 


\section{References}

Al-Adawi S., Rustam B., \& Al-Issa, I. (1997). Mu-Ghayeb: A culture-specific response to bereavement in Oman. The International Journal of Social Psychiatry, 2(43), 144-151.

http://www.doi.org/10.1177/002076409704300207

Al-Krenawi A. (2001). Women from polygamous and monogamous marriages in an out-patient psychiatric clinic. Transcultural Psychiatry, 38(2), 187-199. https://doi.org/10.1177/136346150103800203

Al-Krenawi A., Graham, J. R., \& Slonim-Nevo, V. (2002). Mental health aspects of Arab-Israeli adolescents from polygamous versus monogamous families. The Journal of Social Psychology, 142(4), 446-460. http://www.doi.org/ 10.1080/00224540209603911

Al-Krenawi A., \& Lev-Wiesel, R. (2002). Wife abuse among polygamous and monogamous Bedouin-Arab families. Journal of Divorce \& Remarriage, 36(3/4), 151-165. https://doi.org/10.1300/J087v36n03_09

Al-Lamky A. (2004). Modernization and child neglect in Oman: Trends and implications. International Journal on World Peace, 21(3), 43-53. https://www.jstor.org/stable/20753449

Armstrong, K. (2000). Islam: A short history. Random House.

Bielefeldt, H. (2000). "Western" versus "Islamic" human rights conceptions? A critique of cultural essentialism in the discussion on human rights. Political Theory, 28(1), 90-121. https://doi.org/10.1177/0090591700028001005

Bonney, R. (2004). Reflections on the difference between religion and culture. Clinical Cornerstone, 6(1), 2533. http://www.doi.org/10.1016/s1098-3597(04)90004-x

Bunt, G. (2018) Hashtag Islam: How cyber-Islamic environments are transforming religious authority. The University of North Carolina Press.

Cate, S. R., \& Profanter, A. (2007a). Manifestations of traditional and contemporary cultural processes of marital systems in Dhofar, Oman. In M. Gottwald, M. Klemm, \& B. Schulte (Eds.). KreisLäufe - circular flows. Kapillaren der Weltkultur: Capillaries of world culture (pp. 171-184). Lit Verlag Dr. W. Hopf.

Cate, S. R., \& Profanter, A. (2007b). Manifestations of traditional and contemporary cultural processes of marital systems in Dhofar, Oman. Proceedings of the 7th Conference in Erlangen: "Circular-FlowsCapillaries of World Culture", November 2006. Germany: Friedrich-Alexander-University ErlangenNuernberg.

Chamie, J. (1986). Polygyny among Arabs. Population Studies, 40(1), 55-66. https://www.jstor.org/stable/2174279

Charrad, M. M. (1998). Cultural diversity within Islam: Veils and laws in Tunisia. In H. L. Bodman \& N. Tohidi (Eds.), Women in Muslim societies: Diversity within unity (pp. 63-79). Lynne Reinner.

Fatoye, F. O., Adeyemi, A. B., \& Oladimeji, B. Y. (2004). Emotional distress and its correlates among Nigerian women in late pregnancy. Journal of Obstetrics and Gynecology, 24(5), 504-509. http://www.doi.org/10.1080/01443610410001722518

Goodwin, J. (1994). Price of honour: Muslim women lift the veil of silence on the Islamic world. Warner Books.

Grossbard-Shechtman, S., \& Neuman, S. (1998). The extra burden of Moslem wives: Clues from Israeli women's labor supply. Economic Development and Cultural Change, 46(3), 491-518.

Hassouneh-Phillips D. (2001). Polygamy and wife abuse: A qualitative study of Muslim women in America. Health Care for Women International, 22(8), 735-748. https://doi.org/10.1080/073993301753339951

Herrera L. (2014). Wired citizenship: Youth learning and activism in the Middle East. Routledge.

Hilsdon A-M., \& Santi, R. (2006). Introduction special issue on Islam, gender and human rights. Women's Studies International Forum, 29(4), 331-338. http://www.doi.org/10.1016/j.wsif.2006.05.009

Hoodfar, H. (1997). The impact of male migration on domestic budgeting: Egyptian women striving for an Islamic budgeting pattern. Journal of Comparative Family Studies, 28(2), 74-98. https://www.jstor.org/stable/41603505

Husain, F. A. (2000). Reproductive issues from the Islamic perspective. Human Fertility, 3(2), 124-128. https://doi.org/10.1080/1464727002000198831 
Kazi, S. (1997). Muslim law and women living under Muslim laws. In Afkhami Mahnaz \& E. Friedl (Eds.), Women and the politics of participation: Implementing the Beijing platform (pp. 141-146). Syracuse University Press.

Kosack, G. (1999). Wird die polygynie in der modernen gesellschaft überleben? Überlegungen zur mehrfrauenehe am beispiel der mafia in nordkamerun. Internationale Zeitschrift für Völker- und Sprachenkunde, 94(4/6), 554-563.

Lippman, T. W. (1995). Understanding Islam: An introduction to the Muslim world. Penguin Books.

Low, B. S. (2005). Women's lives there, here, then, now: A review of women's ecological and demographic constraints cross-culturally. Evolution and Human Behavior, 26(1), 64-87. https://doi.org/10.1016/j.evolhumbehav.2004.08.011

Mammen, K. (2019). All for one or each for her own: Do polygamous families share and share alike? Journal for the Advancement of Developing Economies, 8(1).

https://academicworks.cuny.edu/cgi/viewcontent.cgi?article=1222\&context=si_pubs

Marcotte, R. D. (2001). Shahrur, the status of women, and polygamy in Islam. Oriente Moderno, 20(2-3), 313328.

Mashhour, A. (2005). Law and gender equality: Could there be a common ground?: A study of divorce and polygamy in shari'a law and contemporary legislation in Tunisia and Egypt. Human Rights Quarterly, 27(2), 562-596. https://www.jstor.org/stable/20069797

Mayer, A. E. (1995). Islam and human rights: Tradition and politics. Westview Press.

Meekers, D., \& Franklin, N. (1995). Women's perceptions of polygyny among the Kaguru of Tanzania. Ethnology, 34(4), 315-329. https://doi.org/10.2307/3773944

Omari, C. K. (1991). The family in Tanzania. International Journal of Sociology of the Family, 21(2), 55-71.

Peterson, J. E. (2004). Oman's diverse society: Southern Oman. Middle East Journal, 2(58), 254-269.

Profanter, A., \& Cate, S.R. (2009a). Women's experiences of justice and injustice in a polygynous Bedouin-tribal society. In L. Dresdner \& L. Peterson (Eds.), (Re)Interpretations: The shapes of justice in women's experience (p. 133-150). Cambridge Scholars Publishing.

Profanter, A. \& Cate S. R. (2009b). "Deal justly with them": (In)justice in polygyny-The male perspective. The Journal of Social Psychology, 149(3), 223-241. https://doi.org/10.3200/SOCP.149.3.323-342

Sueyoshi, S., \& Ohtsuka R. (2003). Effects of polygyny and consanguinity on high fertility in the rural Arab population in south Jordan. Journal of Biosocial Science, 35(4), 513-526. http://www.doi.org/10.1017/s0021932003005911

Shahrour, M. (1990). Al-Kitabu wa Al-Quran (The book and the Qur'an). Dar Al-Ahali.

Shalhoub-Kevorkian, N. (1997). Wife abuse: A method of social control. Israel Social Science Research, 1(12), 59-72.

Shukri, A. M., \& Owoyemi, M. Y. (2014). Sisters in Islam's quest for the reinterpretation of the Qur'an and hadith: An analysis of their views on equality, women judges, and polygamy. Kajian Malaysia: Journal of Malaysian Studies, 32(1), 55-80.

Verma, J. M. S. (2000). Islam and Muslim women in the modern world. The Eastern Anthropologist, 53(3/4), 491-501.

Waines, D. (1982). Through a veil darkly: The study of women in Muslim societies. A review article. Comparative Studies in Society and History,24(4), 642-659. https://www.jstor.org/stable/178432

Yusuf, A.A. (1983). The Holy Qur'an: Text, translation, and commentary. Dar Al-Mushaf. 